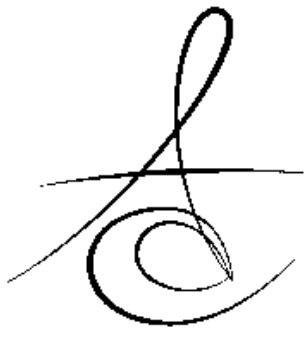

\title{
ÇOCUK HASTALARDA ODONTOMALARIN DEĞERLENDİRİLMESİ: RETROSPEKTİF-KESİTSEL BİR ÇALIŞMA
}

\author{
THE EVALUATION OF ODONTOMAS IN PEDIATRIC PATIENTS: \\ A RETROSPECTIVE-CROSS SECTIONAL STUDY
}

\author{
Dr. Öğr. Üyesi Derya CEYHAN*
}

\author{
Dt. Canan AKDİK*
}

Prof. Dr. Zuhal KIRZIOĞLU*

Makale Kodu/Article code: 3809

Makale Gönderilme tarihi: 15.08 .2018

Kabul Tarihi: 29.01.2019

\section{öz}

Amaç: Bu çalışmada; odontoma tanısı almış hastaların klinik ve radyolojik özelliklerini, uygulanan tedavileri, bu tedavilerin prognozunu sunmak ve klinisyenlere yol göstermek amaçlandı.

Gereç ve Yöntem: Kliniğimize 2003-2018 yılları arasında başvurup odontoma veya odontoma ile ilişkilendirilen sürme problemleri, maloklüzyonlar, sürnümerer dişler gibi problemleri bulunan 1040 hastaya ait kayıtlar tarandı. Kayitları tam, radyografileri standart olan ve odontoma tanısı doğrulanan 36 hasta çalışmaya dâhil edildi. Hastaların kayıtlarından; sosyo-demografik bilgileri, medikal durumları, diş hekimine başvurma nedenleri, uygulanan tedaviler ve tedavilerin prognozu elde edilerek hazırlanan formlara kaydedildi. Radyografilerden; odontomaların lokalizasyonu, dişlenme üzerindeki etkileri, eşlik eden diğer dişsel anomaliler değerlendirilerek formlara eklendi. Veriler istatistiksel olarak analiz edildi.

Bulgular: Çalışmaya dâhil edilen 4-17 yaş aralığındaki 24'ü kadın, 12'si erkek olan 36 hastanın 33'ünün sağlıklı olduğu, hastalardan 1'inin travma, 7'sinin diş sürmemesi, 28 'inin diş çürüğü şikayetiyle başvurduğu belirlendi. Diş sürme problemi saptanan 20 hastada ve çapraşıklık saptanan 6 hastada, odontoma şüphesi nedeniyle radyografik değerlendirme yapıldığı ve odontoma tespit edildiği görüldü. Hastaların 22'sinde görülen kompound odontomaların \%48'inin üst çene kesici dişler bölgesinde, 14'ünde görülen kompleks odontomaların \%31'inin üst çene kesici dişler ve \%31'inin de alt çene azı dişler bölgesinde bulunduğu saptandı. En sık ortaya çıkan klinik bulgunun daimi diş sürememesi, radyolojik bulgunun daimi diş germ çeperinde genişleme olduğu görüldü. Odontomaya en sık eşlik eden dişsel anomaliler dens invaginatus ve taurodontizmdi. Hastaların 22'sinde cerrahi tedavi, 10'unda cerrahiyi takiben ortodontik tedavi, 3'ünde yalnızca takip, 1 'inde odontomanın daimi diş ile birlikte alınmasını takiben protetik tedavi uygulandığı anlaşıldı.

Sonuç: Odontomaların, rutin klinik ve radyolojik incelemeler ile erken yaşlarda teşhis edilerek takip edilmelerinin ve erken karma dişlenme döneminde müdahale edilmesinin uygun olduğu, aksi durumlarda ortodontik veya protetik tedavi intiyacı duyulduğu anlaşılmaktadır.

Anahtar Kelimeler: Çocuk diş hekimliği, odontojenik benign tümörler, odontoma

\section{ABSTRACT}

Aim: This study aimed to present clinical/radiological features, performed treatments, prognosis of treatments of patients with odontoma and to guide clinicians.

Material and Methods: Records of 1040 patients who referred to our clinic between 2003-2018 years and had odontoma or problems related to odontoma such as eruption problems, malocclusions, surnumerary teeth were reviewed. Thirty-six patients whose records were complete, radiographs were standardized and odontoma diagnosis was confirmed were included. Sociodemographic information, medical conditions, reasons for referral to clinic, performed treatments, prognosis of treatments were recorded to prepared forms. Localization of odontomas, effects on dentition, other dental anomalies were examined on radiographs and added to forms. Data were analyzed statistically.

Results: Of 36 patients aged 4-17 years, 24 were females and 12 were males, and 33 were healthy. Reasons for referral to clinic were trauma, eruption problem, and caries in 1, 7, and 28 patients, respectively. Twenty patients with eruption problem and 6 patients with crowded teeth had been evaluated radiographically due to odontoma suspicion and odontoma had been diagnosed. Forty-eight percent of compound odontomas seen in 22 patients were located in maxillary incisor teeth region, and $31 \%$ of complex odontomas seen in 14 patients were located in maxillary incisor teeth region and $31 \%$ were located in mandibular molar teeth region. Most common clinical finding was eruption problem, radiological finding was enlargement of permanent tooth germ wall, and dental anomalies were dens invaginatus and taurodontism. Surgical treatment in 22 patients, surgical and orthodontic treatment in 10 , only follow-up in 3, surgical and prosthodontic treatment in 1 had been performed.

Conclusion: Odontomas should be diagnosed and followed up with routine clinical/radiological examinations at early ages and treated in early mixed dentition period, otherwise orthodontic/prosthodontic treatments are needed.

Keywords: Pediatric dentistry, odontogenic benign tumors, odontoma

*Süleyman Demirel Üniversitesi, Diş Hekimliği Fakültesi, Pedodonti Anabilim Dalı, Isparta. 


\section{GİRİŞ}

Odontomalar, ileri derecede farklılaşma gösteren epitelyal ve mezenşimal hücrelerden gelişen ve odontojenik benign tümörler sınıfında yer alan yapılardır. Sınırlı ve yavaş büyümesi ile mine, dentin, sement ve pulpa gibi tüm odontojenik dokuları içermesi nedeniyle Dünya Sağlık Örgütü tarafından gerçek bir tümör değil, hamartomatöz bir lezyon veya malformasyon olarak tanımlanmaktadır. ${ }^{1}$ Kompound ve kompleks olmak üzere iki alt kategoride değerlendirilen odontomaların etiyolojisi tam olarak bilinmemekle birlikte, genetik ve çevresel faktörlerin etkili olabileceği düşünülmektedir. ${ }^{2}$ Kompound odontomanın, bir bağ dokusu ile birbirlerine sıkı sıkıya bağlanmış çok sayıda küçük diş benzeri yapılardan oluştuğu, kompleks odontomanın ise olgun odontojenik dokuların tek bir amorf kütlesi şeklinde, yapısal düzeni olmayan lezyonlar olduğu belirtilmiştir. ${ }^{3}$ Radyolojik bulgularının, gelişim evrelerine ve mineralizasyon derecelerine bağlı olduğu bilinmektedir. ${ }^{4}$

Odontomalar asemptomatik seyir gösterdiklerinden rutin incelemeler sırasında genellikle tesadüfen saptanmaktadırlar. Bununla birlikte dişlerde sürme gecikmesi, gömülü kalma, yer değişikliği, kapanış bozukluğu ve periodontal problemler ile ilişkilendirilmişlerdir. ${ }^{5}$ Travma, ankiloz, dilaserasyon, malpozisyon, odontojenik tümörler, kalsifiye kitleler, sürnümerer dişler, süt dişlerinin erken kaybı nedeniyle skar dokusu oluşumu ve yer darlığı dişlerin gömülü kalmasına neden olan diğer faktörlerdir ${ }^{6}$ ve odontomalar ile bağlantılı oldukları düşünülebilir. Klinisyenlerin bu bulgular ile karşılaştıklarında odontomaların akla gelmesi ve özelliklerinin bilinmesi, bu patolojinin tesadüfen değil erken dönemde teşhis edilmesini ve takibe alınmasını sağlamaktadır. Çocuk hastaların küçük yaşlardan itibaren klinisyenler tarafından değerlendirilmesi, bu açıdan önem taşımaktadır.

Bu çalışmada; odontoma tanısı almış hastaların klinik ve radyolojik özelliklerini, uygulanan tedavileri, bu tedavilerin prognozunu sunmak ve klinisyenlere yol göstermek amaçlandı.

\section{GEREÇ ve YÖNTEM}

Araştırma için etik kurul onayı, Süleyman Demirel Üniversitesi Tıp Fakültesi Klinik Araştırmalar Etik Kurulundan alındı (14.02.2018 tarihli ve 42 sayılı karar). Pedodonti Anabilim Dalına 2003-2018 yılları arasında başvurup odontoma veya odontoma ile ilişkilendirilen sürme problemleri, maloklüzyonlar ve sürnümerer dişler gibi problemleri bulunan 1040 hastaya ait kayıtlar tarandı. Bu hastalardan kayıtları tam, radyografileri standart olan ve takip seanslarında odontoma tanısı doğrulanan 36 hasta çalışmaya dâhil edildi.

Hastaların kayıtlarından; sosyo-demografik bilgileri, medikal durumları, diş hekimine başvurma nedenleri ve uygulanan tedaviler öğrenilerek hazırlanan bilgi edinme formlarına kaydedildi. Tedavilerin progno$\mathrm{zu}$, kontrol randevularından elde edilen bilgilerden sağlandı. Herhangi bir artefaktın olmadığı, ideal radyografik kalitedeki panoramik radyografilerden; odontomaların lokalizasyonu, dişlenme üzerindeki etkileri ve eşlik eden diğer dişsel anomaliler değerlendirilerek formlara eklendi.

Veriler kaydedilerek SPSS paket programının 23.0 sürümü (IBM SPSS Inc., Chicago, USA) ile değerlendirildi. Değerlendirme kriteri olarak tanımlayıcı istatistikler kullanıldı. Kategorik veriler adet ve yüzdeleri ile, yaş ise ortalama ve standart sapması ile birlikte sunuldu.

\section{BULGULAR}

Çalışmaya dâhil edilen 36 hasta 4-17 yaş aralığında (ort. 10.74 \pm 3.18 ) olup 24'ü kadın, 12'si erkekti. Bu hastalardan 33'ünün herhangi bir sağlık probleminin olmadığı, 1'inde gelişim geriliği, 1'inde mental retardasyon ve 1 'inin akciğerinde kitle olduğu görüldü. Kliniğe başvurma nedenleri değerlendirildiğinde; hastaların 1'inin travma, 7'sinin diş sürmemesi, 28'inin ise diş çürüğü şikayeti ile başvurduğu belirlendi. Klinik muayenesinde diş sürme problemi saptanan 20 hastada ve çapraşıklık saptanan 6 hastada, odontoma şüphesi nedeniyle radyografik değerlendirme yapıldığı ve odontoma tespit edildiği anlaşıldı.

Odontoma tiplerinin yaşlara göre lokalizasyonu Tablo 1'de gösterilmektedir. Odontoma saptanan hastalardan yalnızca 1 'inin süt dişlenme döneminde olduğu, diğer hastaların karma ve daimi dişlenme döneminde olduğu, mental retarde olan 1 hastada üst ve alt çene azı dişler, akciğerinde kitle olan 1 hastada da üst ve alt çene kanin diş ve alt çene azı dişler bölgeleri olmak üzere birçok bölgede odontoma bulunduğu belirlendi. Odontomaların en fazla üst çene kesici dişler bölgesinde görüldüğü, alt çene kesici dişler bölgesinde ise görülmediği saptandı. Hastaların

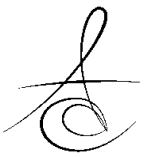


22'sinde görülen kompound odontomaların (Resim 1) $\% 48$ 'inin üst çene kesici dişler bölgesinde, 14'ünde görülen kompleks odontomaların (Resim 2) \%31'inin üst çene kesici dişler ve $\% 31^{\prime}$ inin de alt çene azı dişler bölgesinde yer aldığı görüldü. Yirmi sekiz hastada (\%78) odontomalara diğer dişsel anomalilerin eşlik ettiği belirlendi. Bu hastaların 17'sinde (\%61) dens invaginatus, 2'sinde (\%7) taurodontizm, 7'sinde (\%25) dens invaginatus ve taurodontizm, 1 'inde (\%3.5) dens invaginatus ve hipodonti, 1 'inde (\%3.5) dens invaginatus, taurodontizm ve hipodonti anomalilerine rastlandı. Odontomaların sebep olduğu klinik ve radyolojik bulgular Tablo 2'de gösterilmektedir. En sık ortaya çıkan klinik bulgunun daimi diş sürememesi, radyolojik bulgunun ise daimi diş germ çeperinde genişleme olduğu görüldü.

Tablo 1. Odontoma tiplerinin yaşlara göre lokalizasyonları

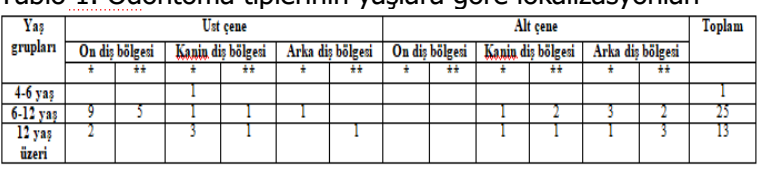

*Kompound odontoma **Kompleks odontoma

Tablo 2. Odontomaların sebep olduğu klinik ve radyolojik bulgular
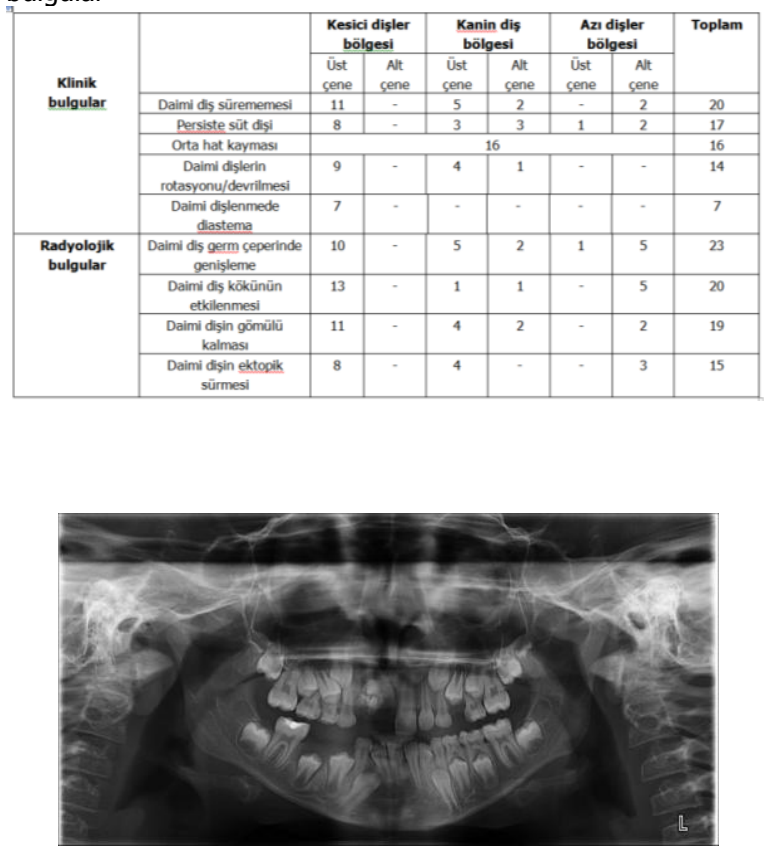

Resim 1. Üst çene kesici dişler bölgesinde kompound odontoma

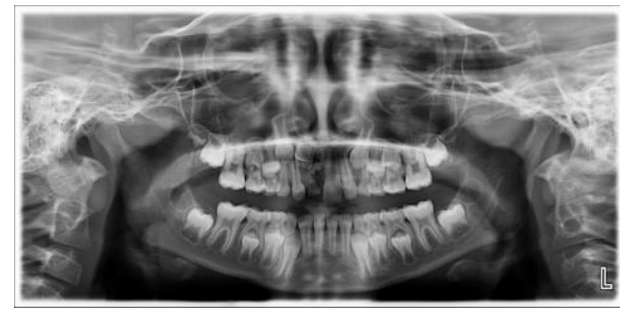

Resim 2. Üst çene kesici dişler bölgesinde kompleks odontoma

Odontomaların tedavisinde; 21 hastada odontomanın cerrahi olarak alındığı ve takip sürecinde, odontoma ile ilişkili daimi dişin germ çeperindeki genişlemenin ortadan kalkarak dişin sürdüğü saptandı. Süt dişlenme döneminde odontoma teşhis edilen 1 hastada, odontomanın ve ilişkili süt dişinin erken karma dişlenme döneminde cerrahi olarak alındığı ve takip sürecinde, daimi dişin sürdüğü görüldü. On hastada odontomanın cerrahi olarak alınmasının ardından ortodontik tedavi ile ektopik sürme, gömülü kalma, rotasyon/devrilme ve orta hat kayması problemlerinin giderildiği belirlendi. Dişlere uzak bölgelerde lokalize ve boyutları küçük olan odontomaların alınmayarak yalnızca takip edildiği 3 hastada, 9 yıllık takip sürecinde, odontoma boyutunda veya bulunduğu bölgedeki daimi dişlerde herhangi bir değişiklik meydana gelmediği anlaşıldı. Bir hastada ise odontomanın ve ilişkili daimi dişin cerrahi olarak alınmasını takiben protetik tedavi uygulandığı görüldü.

\section{TARTIŞMA}

Büyüme ve gelişim döneminde olan çocuklarda, çenelerde görülen lezyonların erken teşhisi ve takibi ile ileride oluşabilecek dişsel ve iskeletsel problemlerin önüne geçilebilmektedir. Odontojenik benign tümörler olan odontomaların çocuk hastalarda erken teşhisi bu açıdan önem arz etmektedir.

Odontoma tiplerinin patojeniteleri farklı olduğundan oluşma yaşı ve lokalizasyonu farklılık göstermektedir. Odontomaların genellikle daimi dişlenmede teşhis edildiği, süt dişlenmede nadir görüldüğü bildirilmiştir. ${ }^{7}$ Kompleks odontomaların hamartomatöz bir lezyon olduğu, sıklıkla yetişkin bireylerde ve alt çenede görüldüğü; kompound odontomaların ise dental laminanın lokal hiperaktivitesi nedeni ile oluştuğu ve sıklıkla genç bireylerde ve üst çenede görüldüğü ifade edilmiştir.3,8 Yapılan çalışmalarda, ayrıca, odontomaların sıklıkla üst çene ön bölgede lokalize olduğu, alt

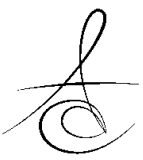


birinci ve ikinci büyük azı dişlerinin nadiren etkilendiği belirlenmiştir. ${ }^{9} 10$ Çalışmamızda da odontomalar çoğunlukla üst çene ön bölgede yer almış, bununla birlikte, üst çene azı dişler bölgesine oranla alt çene azı dişler bölgesinde daha fazla olduğu tespit edilmiştir. Radyolojik incelemelerde, üst çenede bulunan anatomik oluşumlar ve boyun omurlarının görüntüsü nedeniyle, odontomaların gözden kaçırılabileceği dikkate alınmalıdır. Kompound odontomaların, özellikle üst çene kesici dişler bölgesinde, kompleks odontomaların ise özellikle üst çene kesici dişler ve alt çene azı dişler bölgesinde lokalize olduğu ve çoğunlukla karma ve daimi dişlenme döneminde teşhis edildikleri görülmüştür. Çocuk hastaların özel bir problemi olmadığı sürece radyografi alınması ileri yaşlara bırakıldığından, süt dişlenme döneminde odontomalar teşhis edilemeyebilmekte; sürme problemleri, daimi dişlerin sürmesiyle birlikte ortaya çıktığından, odontomalar sıklıkla karma veya daimi dişlenme döneminde teşhis edilebilmektedir. Odontomaların cinsiyete bağlı görülme sıkIığını değerlendiren çalışmalarda karşıt görüşler mevcut olup erkeklerde daha fazla görüldüğünü rapor eden araştırmacıların ${ }^{2,11}$ yanı sıra çalışmamızda olduğu gibi kızlarda daha fazla görüldüğünü bildiren araştırmacılar da mevcuttur. ${ }^{5}$

Gelişen dişlerle beraber odontomaların da ilişkili oldukları dişlerin gelişimi tamamlanana kadar olgunlaşmaya devam ettikleri ve zamanla daha fazla probleme yol açtıkları bildirilmiştir. ${ }^{12} \mathrm{Bu}$ nedenle erken dönemde herhangi bir şikâyete yol açmazken zaman içinde bazı problemlerin yaşanması olası hale gelmektedir. Odontomaların genellikle asemptomatik olduğu, rutin radyolojik muayeneler sırasında teşhis edildiği ve hastaların kliniğe sıklıkla diş sürmesinde gecikme şikâyeti ile başvurdukları bildirilmiştir. ${ }^{13}$ Kayıtlarımıza göre de diş sürmemesi ya da çapraşıklığın sebebi araştırıldığında, yapılan radyografik değerlendirme bu problemlerin odontoma ile ilişkili olduğunu göstermiştir.

Odontomaların sıklıkla daimi dişlerin gömülü kalması, diş sürmesinde gecikme ve persiste süt dişi problemlerine neden olduğu gösterilmiştir. ${ }^{5,14}$ Diğer taraftan, bazı hastalarda, herhangi bir probleme yol açmadığı bildirilmiştir. ${ }^{5}$ Odontomaya bağlı olarak ortaya çıkan klinik ve radyolojik bulgular açısından elde ettiğimiz sonuçlar bu çalışmalar ile benzer olup 3 hastada odontoma ile ilgili herhangi bir bulguya rastlanmamıştır. Çalışmamızda, odontoma ile ilişkilendirilen sürme problemleri, maloklüzyonlar ve sürnü- merer dişler gibi problemleri bulunan 1040 hasta olmasına rağmen bu hastalardan yalnızca 36'sında odontoma tanısı doğrulanmıştır. Odontomaya en sık eşlik eden dişsel anomaliler ise dens invaginatus ve taurodontizm olmuştur. Hastaların \%78'ine eşlik eden bu dişsel anomaliler ile karşılaşıldığında odontoma şüphesi de akla gelmelidir. Dens invaginatus ve odontomanın çoğunlukla üst çene ön bölgede yer alması, üst çenede alt çeneye göre daha fazla anatomik oluşum bulunması nedeniyle üst çenenin gelişimsel bozukluklara daha yatkın olması ile ilişkilendirilebilir. Odontoma ile dens invaginatus ve taurodontizm arasındaki ilişkinin, dental epitelin büyümesini etkileyen aynı genetik kökene dayanabileceği varsayılabilir.

Odontomalar genellikle kemik içi yerleşimli lezyonlar olmakla beraber, yumuşak dokularda lokalize olanlar da bildirilmiştir. ${ }^{15,16}$ Kliniğimizde teşhis edilen odontomaların kemik içi yerleşimli olduğu, tedavi edilmeyip yalnızca takip edilen hastalarda takip sürecinde odontoma boyutunda veya bulunduğu bölgedeki dişler üzerinde herhangi bir değişiklik meydana gelmediği, lezyonun kendi kendini sınırladığı anlaşılmıştır.

Sürnümerer dişler odontomalar ile benzer klinik ve radyolojik bulgulara sebep olmaktadır. Benzer bulgulara yol açmaları ve benzer özellikler göstermeleri, ortak kökenli olup olmadıkları ile ilgili hipotezler öne sürülmesine neden olmuştur. Epidemiyolojik, klinik, immüno-histokimyasal ve genetik verilerin, sürnümerer dişler ve odontomaların ortak bir kökeni olduğunu düşündürdüğü bildirilmiştir. ${ }^{14}$ Odontomaların tamamen kalsifiye olana kadar büyümeleri devam etmektedir ve bu özellik sürnümerer dişler için de geçerlidir. Ayrıca sürnümerer dişler, düzensiz morfolojileri nedeniyle odontomalar ile karıştırılabilmektedir. Radyolojik değerlendirmemizde, kompound odontomaya sahip hastaların \%27'sinde, sürnümerer diş benzeri yapıların eşlik ettiği görülmüştür. Bu durum, dental lamina hiperaktivitesine bağlı olarak bu iki dişsel anomalinin ortak kökenli olabileceğini hatırlatmaktadır.

Odontomalar hem epitelyal hem de mezenşimal hücrelerden oluşan yalancı tümörler olup nadiren kalsifiye odontojenik veya dentigeröz kist gibi patolojilerin gelişimine yol açtıkları bildirilmiştir. ${ }^{9}$ Çalışmamızda olduğu gibi, cerrahi olarak çıkarılıp takip edildiklerinde, odontomaların nüksetme olasılığının olmadığı veya az olduğu rapor edilmiştir. ${ }^{6,17}$ Odontomanın çıkarılmasının ardından spontan diş sürmesinin gözlenebildiği ancak ortodontik yaklaşımın doğru diş 
konumlandırması için bazı olgularda gerekli olduğu açıktır. Çalışmamızda da bir grup hastada odontomaların cerrahi olarak alındığı ve takip edildiği, bir grup hastada cerrahi ve ortodontik tedavi uygulandığı, 3 hastada ise odontomaların yalnızca takip edildiği ve takip sürecinde herhangi bir problem ile karşılaşılmadığı belirlenmiştir. Erken karma dişlenme döneminde tanısı konulan 10 hastada, odontomanın takibi yapılarak uygun dönemde çıkarılması ile ortodontik veya protetik tedavi ihtiyacı olmaksızın dişlenmenin düzenlendiği görülmüştür.

\section{SONUÇ}

Odontomaların rutin klinik ve radyolojik incelemeler ile erken yaşlarda teşhis edilerek takip edilmelerinin, dişsel problemler oluşmadan veya hafif düzeyde iken erken karma dişlenme döneminde müdahale edilmesinin uygun olduğu, aksi durumlarda ortodontik veya protetik tedavi ihtiyacı duyulduğu anlaşılmaktadır.

Derya Ceyhan: ORCID ID: 0000-0002-4489-3248

Canan Akdik: ORCID ID: 0000-0002-6824-9246

Zuhal Kırzıoğlu: ORCID ID: 0000-0002-3726-2392

\section{KAYNAKLAR}

1. Tomizawa M, Otsuka Y, Noda T. Clinical observations of odontomas in Japanese children: 39 cases including one recurrent case. Int J Paediatr Dent 2005;15:37-43.

2. Chaudhary $M$, Chaudhary SD, Singh A, Chaudhary M. Essentials of pediatric oral pathology. $1^{\text {st }}$ ed. New Delhi; Jaypee Brothers Medical Publishers: 2012. p. 214-15.

3. Philipsen HP, Reichart PA, Praetorius F. Mixed odontogenic tumours and odontomas. Considerations on interrelationship. Review of the literature and presentation of 134 new cases of odontomas. Oral Oncol 1997;33:86-99.

4. Kodali RM, Venkat Suresh B, Ramanjaneya Raju P, Vora SK. An unusual complex odontoma. J Maxillofac Oral Surg 2010;9:314-7.

5. An SY, An CH, Choi KS. Odontoma: a retrospective study of 73 cases. Imaging Sci Dent 2012;42:7781.

6. Huber KL, Suri L, Taneja P. Eruption disturbances of the maxillary incisors: a literature review. J Clin Pediatr Dent 2008;32:221-30.

7. Hisatomi M, Asaumi JI, Konouchi H, Honda $\mathrm{Y}$, Wakasa T, Kishi K. A case of complex odontoma associated with an impacted lower deciduous second molar and analysis of the 107 odontomas. Oral Dis 2002;8:100-5.

8. Gonzalez-Alva $P$, Inoue $H$, Miyazaki $Y$, Tsuchiya $H$, Noguchi $\quad$, Kikuchi K, Ide $F$, Ishihara S, Katayama T, Sakashita H, Kusama K. Podoplanin expression in odontomas: clinicopathological study and immunohistochemical analysis of 86 cases. J Oral Sci 2011;53:67-75.

9. Yeung $\mathrm{KH}$, Cheung RC, Tsang MM. Compound odontoma associated with an unerupted and dilacerated maxillary primary central incisor in a young patient. Int J Paediatr Dent 2003;13:20812.

10. Mehra $P$, Singh $H$. Complex composite odontoma associated with impacted tooth: a case report. N Y State Dent J 2007;73:38-40.

11. Paolo B, Emanuele Z, Fabio R, Cesare G. Complex and compound odontomas. J Craniofac Surg 2012;23:685-8.

12. Baldawa RS, Khante KC, Kalburge JV, Kasat VO. Orthodontic management of an impacted maxillary incisor due to odontoma. Contemp Clin Dent 2011;2:37-40.

13. Kulkarni VK, Vanka A, Shashikiran ND. Compound odontoma associated with an unerupted rotated and dilacerated maxillary central incisor. Contemp Clin Dent 2011;2:218-21.

14. Pippi R. Odontomas and supernumerary teeth: Is there a common origin? Int J Med Sci 2014;11: 1282-97.

15. Kintarak S, Kumplanont $P$, Kietthubthew $S$, Chungpanich S. A nodular mass of the anterior palatal gingiva. Oral Surg Oral Med Oral Pathol Oral Radiol Endod 2006;102:3-6.

16. Raval N, Mehta D, Vachhrajani K, Nimavat A. Erupted odontoma: a case report. J Clin Diagn Res 2014;8:101.

17. Üngör C, Kılıç İ. Kompleks ve Kompaund Odontoma: Vaka Serisi. J Dent Fac Atatürk Uni 2013;7:5-10.

\section{Yazışma Adresi}

Dr. Öğr. Üyesi Derya Ceyhan

Süleyman Demirel Üniversitesi, Diş Hekimliği Fakültesi, Pedodonti Anabilim Dalı, Isparta.

Telefon No.: 02462118837

e-mail: derya_ceyhan@yahoo.com deryaceyhan@sdu.edu.tr 